\title{
Effect of Heparin and Heparin Fractions on
}

\section{Platelet Aggregation}

\author{
Edwin W. Salzman, Robert D. Rosenberg, Marianne H. Smith, Jack N. Lindon, \\ and LeONARD FAVREAU, Departments of Surgery and Medicine, Beth Israel \\ Hospital, Sidney Farber Cancer Institute, and Harvard Medical School, \\ Boston, Massachusetts
}

\begin{abstract}
A B S T RA C T Porcine intestinal mucosal heparin induced aggregation of platelets in citrated platelet-rich plasma and enhanced platelet aggregation and serotonin secretion induced by other agents. This action of heparin was blocked by substances that elevate platelet cyclic AMP and by EDTA but not by inhibitors of platelet cyclooxygenase. The effect was not inhibited by apyrase or by $N$-amylthio-5'-AMP and therefore did not require the action of $A D P$, nor was there activation of platelet phospholipase. Platelet aggregation by heparin required a plasma cofactor different from the cofactor required for ristocetin.

Fractionation of heparin yielded preparations that varied in molecular weight and, within a given molecular weight fraction, in affinity for antithrombin III. Fractions of high molecular weight (average 20,000) were more reactive with platelets than were fractions of low molecular weight $(7,000)$. Anticoagulant activity did not parallel the platelet reactivity of heparin fractions. Among high molecular weight fractions, preparations of high or low antithrombin affinity were equally active in induction of platelet aggregation. In low molecular weight fractions, there was an inverse relationship between platelet reactivity and anticoagulant activity in normal platelet-rich plasma, but, in plateletrich plasma depleted of antithrombin, low molecular weight fractions of high and low antithrombin affinity reacted equally with platelets. These results suggest that formation of an antithrombin-heparin complex protected platelets from aggregation by heparin.

Selection of heparin fractions of low molecular weight and high antithrombin affinity may improve anticoagulant therapy and development of thromboresistant heparin-coated artificial materials.
\end{abstract}

This paper was presented in part at an Annual Meeting of the American Heart Association, Dallas, Tex., in November 1978, and published as an abstract (Circulation. $\mathbf{5 8}$ [Suppl. II]: 206.

Received for publication 27 April 1979 and in revised form 30 July 1979.

\section{INTRODUCTION}

The anticoagulant action of heparin results from its ability to bind and activate a natural inhibitor of the serine proteases involved in the intrinsic coagulation system, so-called "antithrombin III," or "heparin cofactor" (1). Heparin also blocks the action of thrombin on platelets, but many other activities of platelets proceed despite the administration of heparin. The drug does not prevent platelet consumption during extracorporeal circulation for cardiopulmonary bypass (2) or hemodialysis (3), nor does it prevent adherence of platelets to subendothelial connective tissue (4) or to artificial surfaces in vitro $(5,6)$. Administration of heparin leads sometimes to thrombocytopenia $(7-14)$, and there are claims that arterial embolization has been induced by heparin (15-17). Artificial materials with heparin bonded to the surface in an attempt to prevent thrombotic complications of prosthetic devices have been erratic in their performance $(2,18-21)$; even optimistic accounts (22) describe a profound shortening of platelet survival.

In vitro, heparin has been reported to reduce, enhance, or have no effect on platelet aggregation, depending on the system employed for studying it. O'Brien et al. (23) Besterman et al. (24), and Gillett et al. (25) found reduced platelet aggregation and serotonin release by epinephrine and collagen in heparinized platelet-rich plasma (PRP) ${ }^{1}$ but it was later suggested $(26,27)$ that this may have resulted from a partial and incomplete response of the platelets having already occurred. Eika (28) reported that platelets washed and suspended in a buffer were aggregated by high concentrations of heparin and, together with Thomson et al. (29) and Ellison et al. (30), found that enhancement of platelet aggregation in PRP was produced by

\footnotetext{
${ }^{1}$ Abbreviations used in this paper: AT, antithrombin III; GFP, gel filtered platelets; PPP, platelet-poor plasma; PRP, platelet-rich plasma.
} 
lower concentrations. Lindsay et al. (18) described enhancement of platelet aggregation during extracorporeal circulation with a heparin-coated circuit, presumably attributable to the action of desorbed heparin, although they claimed a reduction in reactivity of the surface itself as a result of heparin binding.

A possible explanation for the varied results in different laboratories was suggested by Lam et al. (31), who reported that heparin is a heterogeneous mixture of polysaccharide chains that vary in their affinity for antithrombin III and thus in their potency as anticoagulants. They observed that $85 \%$ of the anticoagulent activity of porcine intestinal mucosal heparin resides in $30 \%$ of the mass and that two-thirds of the material is virtually inactive as an anticoagulant. Confirmation of this report was provided by Andersson et al. (32) and by Höök et al. (33). Subsequently, Rosenberg and Lam (34) examined the structure of heparin fractions of $7,000 \mathrm{~mol}$ wt with high and low anticoagulant activity and demonstrated subtle differences in primary structure.

We undertook to study the reactivity with blood platelets of different subfractions of heparin, separated on the basis of molecular weight and according to antithrombin binding capacity. Different subfractions of heparin were found to interact with platelets to different degrees, which did not parallel the anticoagulant activity of the preparations.

\section{METHODS}

Collection of blood and preparation of citrated PRP and platelet-poor (platelet count $<10,000 / \mu \mathrm{l}$ ) plasma (PPP) were as previously described (35). In some experiments, platelets were separated from plasma by filtration through a column of Sepharose 2B (Pharmacia Fine Chemicals, Div. of Pharmacia, Inc., Piscataway, N. J.) by the technique of Tangen et al. (36) as modified by Lindon et al. (37) and were suspended in Tyrode's buffer, $\mathrm{pH} 7.4$, containing $1 \mathrm{mg} / \mathrm{ml}$ glucose and $10.9 \mathrm{mM}$ trisodium citrate (gel filtered platelets). Apyrase, $200 \mu \mathrm{g} / \mathrm{ml}$ (see below), was added to the gel filtered platelet suspension to prevent "spontaneous aggregation" (presumably from ADP in the suspending medium) on stirring.

For some experiments, platelets were washed on a discontinuous stepwise bovine albumin gradient (Sigma Chemical Co., St. Louis, Mo.) according to a modification of the technique of Timmons and Hawiger (38) using Tyrode's solution instead of Hepes buffer. Platelets layered above the $40 \%$ albumin zone were recovered by pipette, together with $\sim 100$ $\mu \mathrm{l}$ of the $40 \%$ albumin solution, and were suspended in PPP or Tyrode's solution.

Platelet aggregation was studied by the method of Born and Cross (39), using a two-channel Payton aggregometer and Fisher Recordall 5000 dual-channel recorder (Fisher Scientific Co., Pittsburgh, Pa.). Comparison of slopes of aggregation tracings was by computer-derived least squares linear regression for heparin-induced aggregation and by change in optical density at a fixed time after addition of an aggregating agent (usually 2 or $3 \mathrm{~min}$, whichever gave the clearest discrimination among tracings), for aggregation by other substances. For certain studies of platelet aggregation induced by addition of heparin to citrated PRP or gel filtered platelets (GFP), to be described below, the recorder scale was expanded by setting full scale deflection of the pen equal to the difference in light transmittance between PRP and a 1:1 mixture of PRP with PPP, instead of setting maximal light transmittance equal to the value for PPP, which is customary. Platelets were counted on a Technicon AutoAnalyzer Autocounter (Technicon Instruments Corp., Tarrytown, N. Y.) or on a Coulter counter model B (Coulter Electronics Inc., Hialeah, Fla). Within an experiment, comparison of platelet aggregation was conducted with samples of the same PRP, and therefore samples were always compared at the same platelet count.

The platelet release of $2-\left[{ }^{14} \mathrm{C}\right] 5$-hydroxytryptamine (serotonin) (Amersham Corp., Arlington Heights, Ill.) was measured by the method of Spaet and Zucker (40), expressing results as percent release of serotonin previously taken up by platelets. $\beta$-thromboglobulin in plasma was measured by radioimmunoassay with a reagent kit (Amersham Corp.). Malondialdehyde was measured by the method of McMillan et al. (41).

Phospholipase activity of platelets was measured in PRP and GFP by a modification of the method of Lapetina et al. (42), in which $\left[{ }^{14} \mathrm{C}\right]$ arachidonic acid, $0.74 \mu \mathrm{Ci}$ (Nuchek-Prep, Inc., Elysium, Minn.) (0.0077 mM final) was incubated in PRP at $37^{\circ} \mathrm{C}$ for $30 \mathrm{~min}$, and radioactivity not associated with the platelets was then removed by filtration through a Sepharose 2B column previously equilibrated with citrate PPP or with Tyrode's solution with glucose and citrate (see above). Eicosatetraynoic acid, $100-300 \mu \mathrm{g} / \mathrm{ml}$, was added to the platelet suspension to block both the cyclooxygenase and the lipoxygenase involved in arachidonic acid metabolism (43). The ${ }^{14} \mathrm{C}$-labeled platelets in PRP or GFP were then exposed to $5 \mu \mathrm{m} / \mathrm{ml}$ thrombin or "stock" heparin for $15 \mathrm{~min}$ at $37^{\circ} \mathrm{C}$ and extraced by the method of Lapetina et al. (42). After centrifugation, the supernate was subjected to thin-layer chromatography on a silica gel plate (Analtech, Inc., Newark, Del.) with chloroform:methanol:acetic acid (90:5:5). Free $\left[{ }^{14} \mathrm{C}\right]$ arachidonic acid was identified by reference to standards and counted.

Porcine intestinal mucosal heparin was obtained from Wilson Chemical Co., Chicago, Ill., at an early purification stage before treatment with oxidizing agents and was further purified by cetyl-pyridinium chloride precipitation. Approximately $4 \mathrm{~g}$ of this material was filtered at flow rates of $40 \mathrm{ml} / \mathrm{h}$ through a column of Sephadex G-100 (Pharmacia Fine Chemicals) $(5 \times 190(\mathrm{~cm})$ equilibrated with $0.15 \mathrm{M} \mathrm{NaCl}$ in $0.01 \mathrm{M}$ Tris-HCl, pH 7.5. Fractions of molecular weight $\sim 20,000$ and $\sim 7,000$ were separately pooled, complexed with heparin, and separated by chromatography.

This process was initially conducted by mixing limiting amounts of antithrombin with either of the two heparin fractions at molar ratios of $0.03: 1.0$ in a solution of $0.15 \mathrm{M} \mathrm{NaCl}$ in $0.01 \mathrm{Tris}-\mathrm{HCl}, \mathrm{pH} 7.5$, and $24^{\circ} \mathrm{C}$. Thereafter, bound heparin was separated from uncomplexed mucopolysaccharide and subsequently isolated free of antithrombin by techniques analogous to those reported previously (44). The resultant products attained maximal anticoagulant potency when molar ratios of inhibitor to mucopolysaccharide were set at $<0.10$. Further reductions in this parameter to 0.03 or less did not result in the isolation of heparin species with higher biologic activities. Therefore, the molar ratios of antithrombin to mucopolysaccharide were maintained at 0.08:0.10 for all subsequent separations of high activity material, which represented $-25 \%$ of the heparin with high anticoagulant activity and $8-10 \%$ of the entire pool. Low activity mucopolysaccharide was prepared in a similar manner but used a two- to threefold molar excess of antithrombin to heparin. Material able to interact with antithrombin III (AT) (i.e., moderate anticoagulant activity) was discarded, whereas mucopolysaccharide unable to bind to the inhibitor was harvested. The high activity and low activity products were rechromatographed on 
columns of Sephadex G-100 $(0.55 \times 180 \mathrm{~cm})$ at flow rates of $4 \mathrm{ml} / \mathrm{h}$. The column matrix was previously equilibrated with $0.5 \mathrm{M} \mathrm{NaCl}$ in $0.01 \mathrm{M}$ Tris- $\mathrm{HCl}, \mathrm{pH} \mathrm{7.5}$, and calibrated with heparin standards of known molecular size that had been studied by analytical ultracentrifugation and light scattering. Each of the high molecular weight or low molecular weight fractions appeared to be homogeneous. For comparison, a single lot of pharmaceutical grade porcine mucosal heparin was obtained from commercial sources (Panheparin, Abbott Laboratories, North Chicago, Ill.; lot number 26-428-DB, 1,000 $\mathrm{U} / \mathrm{ml}$, containing $0.9 \%$ benzyl alcohol as a preservative). This is referred to as "stock heparin."

The anticoagulant potency of heparin fractions was estimated in terms of their ability to accelerate the interaction of antithrombin with thrombin compared with a heparin standard of known U.S. Pharmacopeia potency, according to a previously described technique (31).

Prostaglandins $E_{1}$ and $I_{2}$ were obtained from Dr. John Pike, Upjohn Co., Kalamazoo, Mich. $\mathrm{N}$-amylthio-5'-AMP was obtained from Dr. K. Kikugawa, Kohjin Co., Osaka, Japan. Hirudin was purchased from Pentapharm Ltd., Basle, Switzerland, and was used without further purification. Potato apyrase was obtained from Sigma Chemical Co. and was further purified on a fetuin-agarose column to remove platelet-aggregating lectins according to the method of Whigham et al. (45). Ristocetin was purchased from Pacific Hemostasis Labs, Bakersfield, Calif.

Scanning electron microscopy was performed on PRP samples by a previously described technique (46).

AT was purified by affinity chromatography on heparinSepharose according to the method of Rosenberg and Damus (47). It was assayed by radioimmunoassay using antibodies raised in goats against purified antithrombin. Goat immunoglobulin (Ig)G was supplied by Miles Laboratories, Inc., Miles Research Products, Elkhart, Ind., and anti-goat IgG serum prepared in rabbits was supplied by Atlantic Antibodies, Westbrook, Maine. Bound and unbound radioactivity was separated using a double antibody technique. Radiolabeled AT was prepared by chloramine $\mathrm{T}$ iodination (48).

Antithrombin-poor plasma was prepared by passing citrated PPP through a column (1.8 cm Diam and $3.5 \mathrm{~cm}$ long) of heparin-agarose gel prepared by the technique of Lindon et al. (46). Passage of $100 \mathrm{ml}$ of plasma through the column lowered its content of AT to $<8 \mu \mathrm{g} / \mathrm{ml}$ in a typical experiment. Antithrombin-poor PRP was then prepared by gel filtration of albumin-washed platelets in Tyrode's buffer through a Sepharose 2B column previously equilibrated with two column volumes of antithrombin-poor PPP from the same donor. Platelets were thus suspended in autologous plasma depleted of antithrombin or other proteins that adhered to heparin but otherwise intact (49). Preparation of the antithrombin-poor plasma occupied $2-3 \mathrm{~h}$, so a fresh blood sample was obtained for preparation of the albumin-washed platelet suspension.

Statistical analysis was performed on the PROPHET System, a national computer resource sponsored by the Chemical/ Biological Information Handling Program, National Institutes of Health. Comparison of multiple samples was by analysis of variance $(50)$ or by Duncan's multiple range test $(51)$ if normally distributed, and by Doksum's test or the KruskalWallis test (52) for nonparametric analysis if not. Comparison of paired data was by Student's $t$ test (50) if normally distributed, and by the sign rank test (52) if not.

\section{RESULTS}

When $10 \mu \mathrm{g} / \mathrm{ml}$ pharmaceutical grade commercial heparin, stock heparin, was added to citrated PRP at $37^{\circ} \mathrm{C}$, platelet aggregation in varying degrees was always demonstrable, provided the scale of the aggregometer recorder was expanded (details in Methods). Examination of the specimens by phase microscopy confirmed the presence of small platelet aggregates. The process did not reverse despite continued stirring in the aggregometer for up to $30 \mathrm{~min}$. There was no release of $\left[{ }^{14} \mathrm{C}\right]$ serotonin or of $\beta$-thromboglobulin into the plasma in most experiments, but in PRP from a few donors ( $<5 \%$ of experiments), heparin induced twophase aggregation similar to that induced by ADP, and serotonin release was observed.

Fig. 1 illustrates the appearance of platelets aggregated by heparin in citrated PRP and fixed by addition of glutaraldehyde. Normal unstimulated platelets and platelets aggregated by ADP are shown for comparison. Preservation of the discoid shape of native platelets and failure to display the spiculated spherical configuration of platelets exposed to ADP were characteristic of the response to heparin.

When ADP or epinephrine was added to citrated PRP 30-60 s after addition of $10 \mu \mathrm{g} / \mathrm{ml}$ heparin, there was enhancement of the response to these agents, compared with the degree of aggregation observed in the absence of heparin. A typical example of the effect on ADP-induced aggregation is shown in Fig. 2. Release of $\left[{ }^{14} \mathrm{C}\right]$ serotonin was also augmented in the presence of heparin.

Platelet aggregation and secretion in response to heparin were also studied after fractionating heparin according to molecular weight and, within a molecular weight category, according to antithrombin affinity (see Methods). It should be noted that anticoagulant activity in the "low affinity" fractions could result from trace contamination with highly active material. The preparations studied are described in Table I.

Platelet aggregation and secretion of $\left[{ }^{14} \mathrm{C}\right]$ serotonin induced by ADP in citrated PRP were enhanced by prior addition of all the heparin fractions examined,

TABLE I

Antithrombin Activity

\begin{tabular}{cc}
$\begin{array}{c}\text { High molecular weight } \\
\text { (average 20,000) }\end{array}$ & $\begin{array}{c}\text { Low molecular weight } \\
\text { (average 7,000) }\end{array}$ \\
\hline
\end{tabular}

U/mg heparin

\begin{tabular}{lcc} 
High affinity & 736 & 363 \\
& (HMW-HAT) & (LMW-HAT) \\
Low affinity & 20 & 8 \\
& (HMW-LAT) & (LMW-LAT) \\
\hline
\end{tabular}

Abbreviations used in this table: HMW-HAT, high molecular weight and high antithrombin affinity; LMW-HAT, low molecular weight and high antithrombin affinity; HMW-LAT, high molecular weight and low antithrombin affinity; LMWLAT, low molecular weight and low antithrombin affinity. 

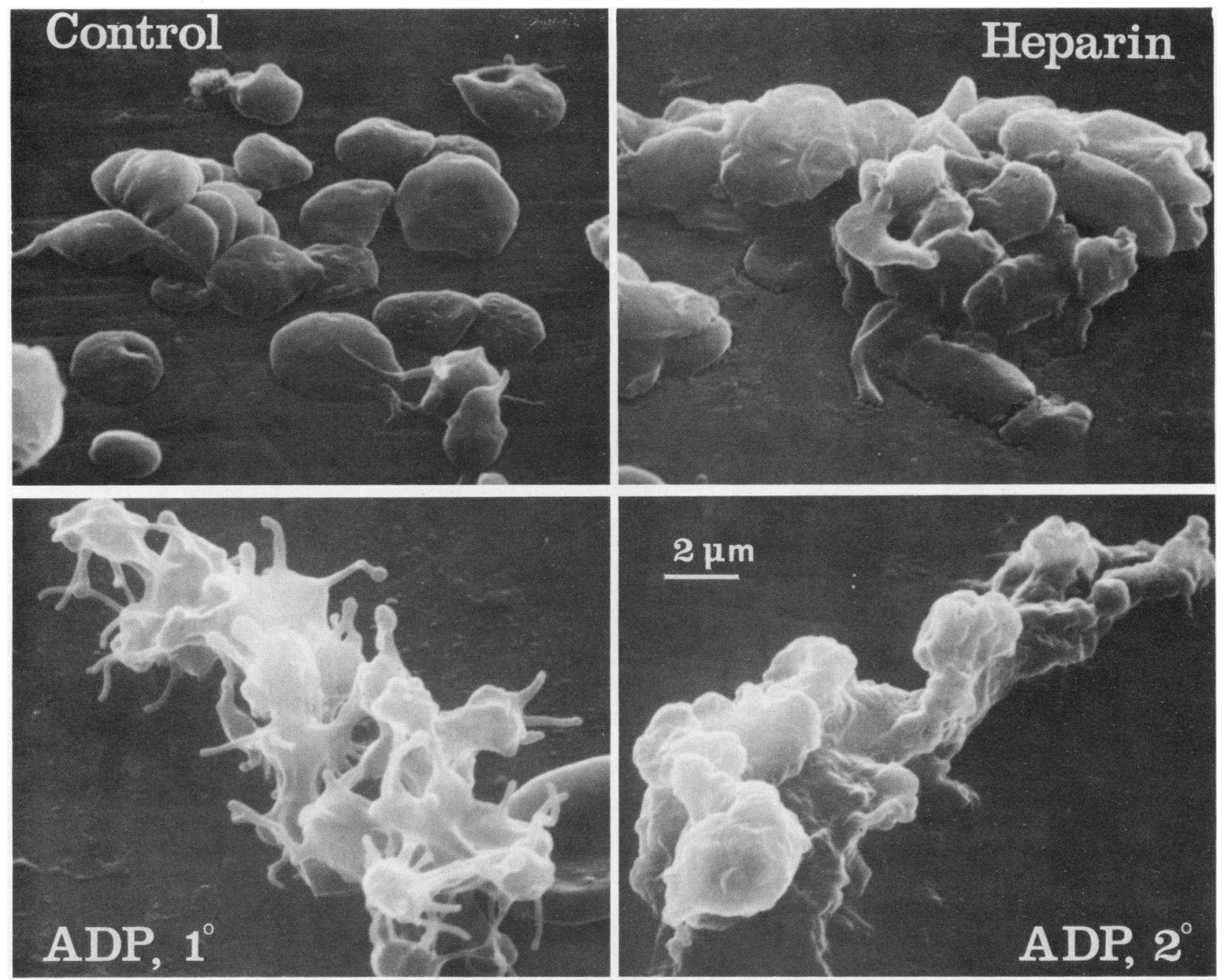

FIGURE 1 Scanning electron micrograph of platelets aggregated by addition of stock heparin to citrated PRP 2 min before fixation with glutaraldehyde. Platelet aggregates induced by $0.5 \mu \mathrm{M}$ $\mathrm{ADP}$ at $2 \mathrm{~min}$ (primary phase) and $2.5 \mu \mathrm{M}$ at $2 \mathrm{~min}$ (second phase) are shown for comparison. $\times 3,000$.

but not to the same extent. The high molecular weight fractions could be subdivided into preparations with either high or low antithrombin affinity (Table I), which were approximately equal in their capacity to enhance the platelet response to other aggregating agents (Table II). Thus the reactivity with platelets did not parallel the anticoagulant activity. Among the low molecular weight fractions, those with low antithrombin affinity were as reactive with platelets as the high molecular weight fractions. However, the low molecular weight fractions of low antithrombin affinity were significantly more potent in enhancing aggregation and serotonin release than were the low molecular weight fractions of high antithrombin affinity (Table II). An inverse relationship of anticoagulant activity and platelet reactivity in the low molecular weight fractions was also observed with enhancement of aggregation induced by epinephrine and collagen.

As with the stock heparin, addition of the heparin fractions to citrated PRP led to platelet aggregation, which occurred without apparent shape change. The sensitivity to heparin-induced platelet aggregation varied widely from blood donor to blood donor. A typical dose-response curve with a high molecular weight fraction of low antithrombin affinity is shown in Fig. 3. The low molecular weight fractions were significantly less active in induction of platelet aggregation than were the higher molecular weight fractions (Table III). Among the high molecular weight fractions, preparations of high and low affinity for antithrombin were not significantly different in their effectiveness as inducers of platelet aggregation. However, as was the 


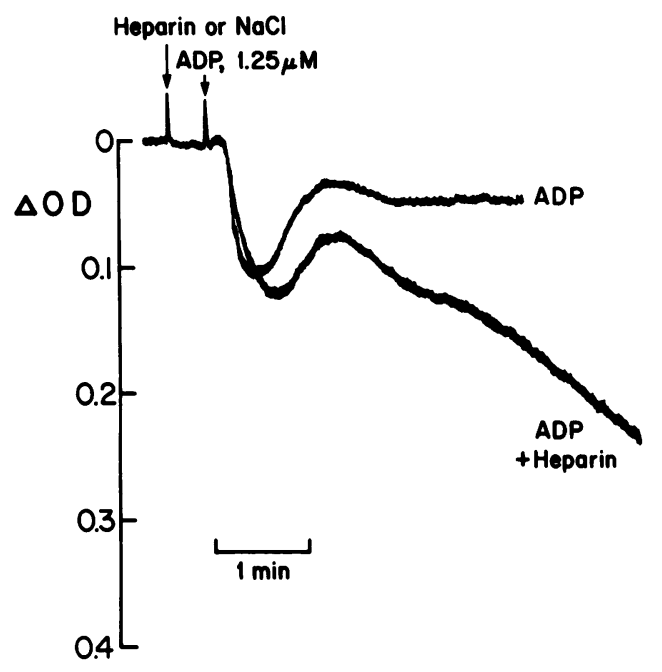

FIGURE 2 Platelet aggregation induced by $1.25 \mu \mathrm{M}$ ADP. In the lower tracing, $10 \mu \mathrm{g} / \mathrm{ml}$ stock heparin was added $1 \mathrm{~min}$ before the addition of ADP.

case in respect to their activity in enhancement of the effects of other platelet stimuli, fractions of low molecular weight and high antithrombin affinity were less reactive in inducing platelet clumping than were those of low antithrombin affinity.

Suspensions of platelets in Tyrode's solution were prepared by Sepharose gel filtration (see Methods). Such platelets aggregated readily upon addition of ADP or collagen, without the need for added plasma cofactors such as fibrinogen. Addition of stock heparin or any of the heparin fractions aggregated such platelets variably and with poor reproducibility. However, when the platelets were first washed in an albumin gradient to remove adsorbed protein before gel filtration (38), addition of heparin in concentrations up to $10 \mu \mathrm{g} / \mathrm{ml}$ never produced platelet aggregation. After albumin

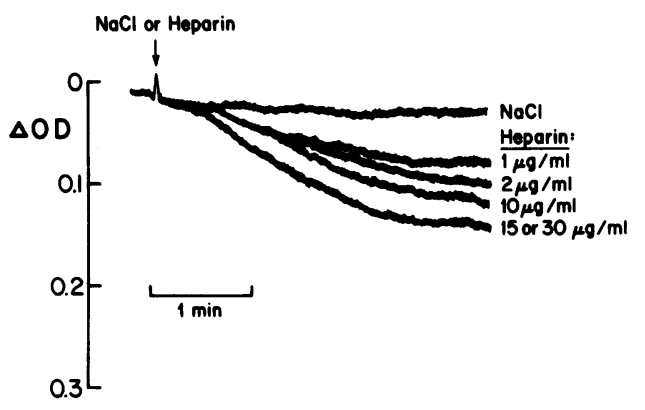

FIGURE 3 Platelet aggregation induced in citrated PRP by the addition of heparin high molecular weight-low antithrombin affinity (HMW-LAT) at various concentrations. The recorder scale is expanded by setting full scale equal to the difference between optical density of PRP and that of a 1:1 mixture of PRP and PPP.

washing and gel filtration, platelets did not aggregate upon addition of ADP or ristocetin. However, if the albumin-washed platelets were gel filtered into Tyrode's buffer containing dilute PPP, maximal responsiveness to ADP and ristocetin was restored when the suspending medium was $25 \%$ plasma. The maximal response to heparin always required at least $75 \%$ plasma (Fig. 4).

Platelets fixed in formaldehyde are known to be aggregated by ristocetin (53). When GFP in Tyrode's solution were incubated overnight in dilute formaldehyde $(0.74 \% \mathrm{vol} / \mathrm{vol}$ in $0.01 \mathrm{M}$ Tris- $\mathrm{HCl}, \mathrm{pH} 7.4,0.15 \mathrm{M} \mathrm{NaCl}$, $\left.4^{\circ} \mathrm{C}\right)(53)$ and then re-filtered into PPP, the formaldehydefixed platelets aggregated upon addition of $1.4 \mathrm{mg} / \mathrm{ml}$ ristocetin but were totally unresponsive to addition of $10 \mu \mathrm{g} / \mathrm{ml}$ heparin.

Platelet aggregation induced in citrated PRP by the addition of either stock heparin or any of the heparin fractions was inhibited in a concentration-dependent fashion by agents that increase platelet cyclic AMP, including prostaglandin $E_{1}$, prostaglandin $I_{2}$, and

TABLE II

Enhancement of ADP-induced Platelet Aggregation and $\left[{ }^{14} \mathrm{C}\right]$ Serotonin Release by Heparin Fractions

\begin{tabular}{|c|c|c|c|c|c|c|}
\hline & \multicolumn{3}{|c|}{ Aggregation } & \multicolumn{3}{|c|}{$\left[{ }^{14} \mathrm{C}\right]$ Serotonin release } \\
\hline & No. & $\Delta O D$, Percent ${ }^{*}$ & $P$ & No. & Percent releaset & $P$ \\
\hline HMW-LAT vs. HMW-HAT $§$ & 7 & $30 \pm 18$ vs. $28 \pm 9$ & NS" & 7 & $19 \pm 12$ vs. $21 \pm 12$ & NS \\
\hline HMW-LAT vs. LMW-LAT & 15 & $33 \pm 21$ vs. $32 \pm 17$ & NS & 6 & $11 \pm 4$ vs. $13 \pm 3$ & 0.060 \\
\hline HMW-HAT vs. LMW-HAT & 17 & $35 \pm 33$ vs. $22 \pm 31$ & $<0.01$ & 13 & $14 \pm 16$ vs. $6 \pm 16$ & $<0.01$ \\
\hline LMW-HAT vs. LMW-LAT & 19 & $24 \pm 22$ vs. $40 \pm 31$ & $<0.05$ & 15 & $7 \pm 13$ vs. $14 \pm 11$ & $<0.01$ \\
\hline
\end{tabular}

Experiments were performed as paired comparisons, and mean values can only be compared within a pair. Analysis is by Student's $t$ test for paired samples. Differences in optical density $(\Delta O D) *$ or percent $\left[{ }^{14} \mathrm{C}\right]$ serotonin release at $3 \mathrm{~min}$ are between sample containing $10 \mu \mathrm{g} / \mathrm{ml}$ heparin (added $1 \mathrm{~min}$ before ADP) and average of at least six controls (ADP without heparin) in the same PRP sample.

$* \Delta \mathrm{OD}$ heparin $-\Delta \mathrm{OD}$ control$/ \Delta \mathrm{OD}$ control $\times 100$, mean $\pm \mathrm{SD}$.

$\$ \%\left[{ }^{14} \mathrm{C}\right]$ serotonin release (heparin) $-\%\left[{ }^{14} \mathrm{C}\right]$ serotonin release (control); mean $\pm \mathrm{SD}$.

$\$$ See Table I for definitions of abbreviations.

" $P>0.10$. 
TABLE III

Platelet Aggregation Induced by Heparin Fractions

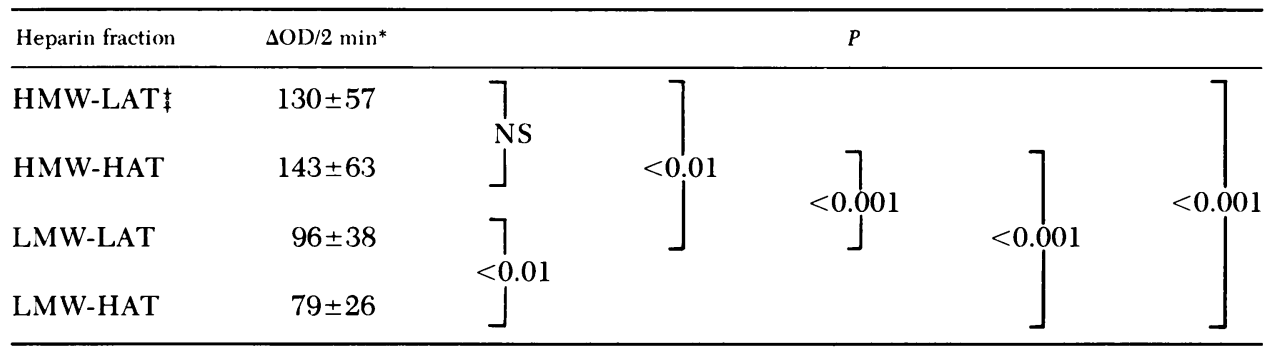

These experiments were performed as four-way comparisons of the heparin fractions in single samples of PRP ( $n=15)$, using an expanded scale on the aggregometer and computing the slope of the curve of change in optical density (in arbitrary units) by least squares linear regression. Significance of differences was determined by analysis of variance and pairwise comparisons. Heparin concentration was $10 \mu \mathrm{g} / \mathrm{ml}$.

* Mean \pm SD.

\$ See Table I for definitions of abbreviations.

dibutyryl cyclic AMP. The platelet response was also inhibited by EDTA at concentrations $>0.01 \mathrm{mM}$. However, there was no inhibition by $10 \mathrm{U} / \mathrm{ml}$ hirudin nor was the platelet response to the heparin fractions suppressed by inhibitors of platelet cyclooxygenase, including aspirin and indomethacin.

The possible involvement of ADP in platelet aggregation induced by the heparin fractions was investigated by addition to citrated PRP of $N$-amylthio- $5^{\prime}$ AMP, a relatively specific inhibitor of ADP-induced

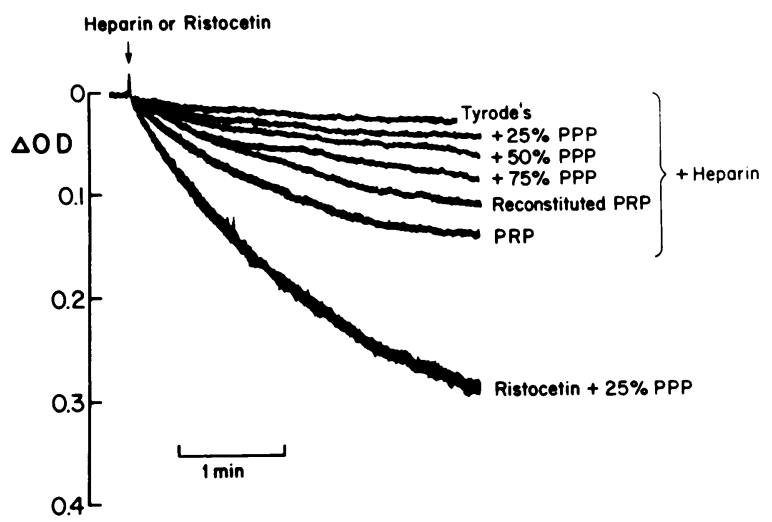

Figure 4 Platelets were washed by centrifugation on an albumin gradient and then passed through a Sepharose gel column (Methods) previously filled with PPP from the same blood donor who provided the platelets or with dilutions of PPP in varying quantities of Tyrode's solution with citrate and glucose. Thus the platelets were ultimately suspended in their own plasma ("reconstituted PRP") or in a plasma/ Tyrode's mixture containing $0,25,50$, or $75 \%$ PPP. Heparin (high molecular weight-low antithrombin affinity; HMW$\mathrm{LAT}$ ), $10 \mu \mathrm{g} / \mathrm{ml}$, or ristocetin, $1.4 \mathrm{mg} / \mathrm{ml}$, was then added in an aggregometer at $37^{\circ} \mathrm{C}$ with stirring. Recorder scale was expanded as in Fig. 3. Platelet counts in reconstituted samples were $141,000 \pm 13,960 \mathrm{SD} / \mu \mathrm{l}$. platelet reactions (54). This compound, which at a concentration of $0.05 \mathrm{mM}$ inhibits both the primary and secondary phase of aggregation produced by ADP but only the second phase of aggregation induced by epinephrine or thrombin, had no effect on the aggregation of platelets induced in PRP by heparin fractions.

Another inhibitor of ADP-induced platelet reactions, apyrase, which hydrolyses ADP and blocks aggregation customarily attributed to platelet-derived ADP (55), also failed to inhibit platelet aggregation induced in citrated PRP by heparin. At concentrations of 210-350 $\mu \mathrm{g} / \mathrm{ml}$, apyrase strongly inhibited both the first and second phases of the platelet aggregation response to ADP, but there was no effect on heparin-induced platelet clumping.

The effect of substances that increase platelet cyclic AMP on heparin's enhancement of the platelet response to other stimuli could not be studied because of direct inhibition of the primary response to the aggregating agent. It was, however, possible to study the enhancement of platelet activity in the presence of aspirin and other nonsteroidal antiinflammatory agents that inhibit only the second phase of platelet aggregation and serotonin secretion by inhibition of platelet cyclooxygenase, and do not prevent so-called "primary aggregation." Addition of stock heparin or heparin fractions to citrated PRP from a subject who had received $0.9 \mathrm{~g}$ aspirin $3 \mathrm{~h}$ earlier significantly reduced the defect in ADP-induced aggregation (Fig. 5). Enhancement of ADP-induced platelet clumping by heparin was evident despite the ingestion of aspirin; there was no amelioration of the defect in serotonin release because of aspirin ingestion.

Heparin activates lipoprotein lipase derived from endothelial cells or liver (56), and we considered the possibility that heparin might also activate platelet 


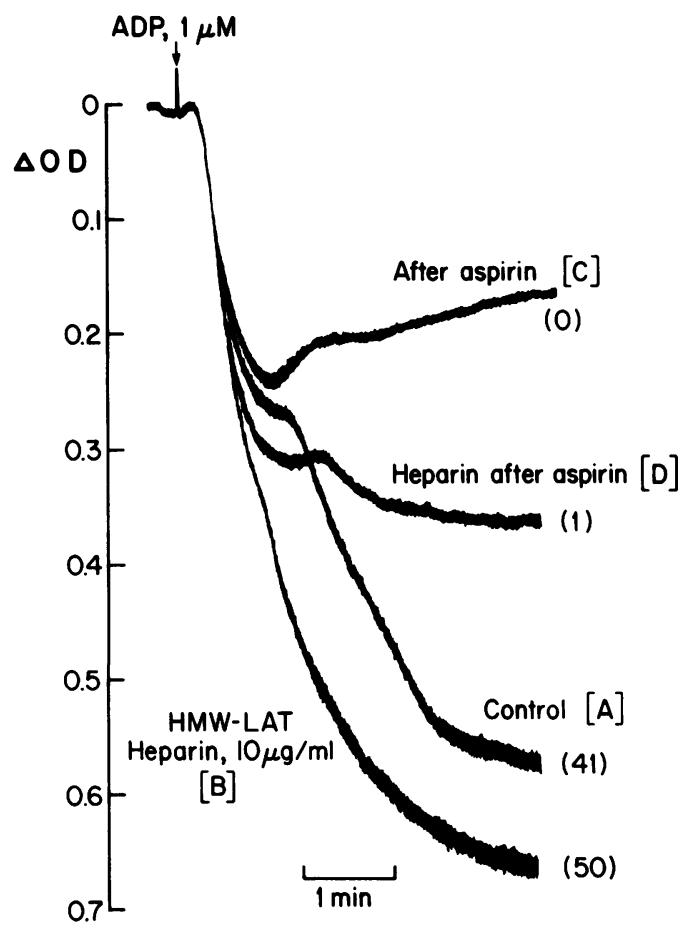

FIGURE 5 ADP-induced platelet aggregation (control) (A) and its enhancement by heparin (high molecular weight-low antithrombin affinity; HMW-LAT) (B). In PRP prepared from a blood sample collected $3 \mathrm{~h}$ after the donor had ingested $0.9 \mathrm{~g}$ aspirin, the second phase of aggregation was inhibited (C). In the presence of heparin (added $1 \mathrm{~min}$ before ADP), ADP produced a second wave of aggregation even after aspirin (D). Figures in parentheses indicate percent release of $\left[{ }^{14} \mathrm{C}\right]$ serotonin.

phospholipases, with subsequent formation of prostaglandin endoperoxides leading to platelet aggregation. After addition of stock heparin or the heparin fractions to platelets in PRP or GFP labeled with $\left[{ }^{14} \mathrm{C}\right]$ arachidonic acid, there was no evidence of phospholipase activation. In a typical experiment, $86 \%$ of the ${ }^{14} \mathrm{C}$ label was incorporated by the platelets, and $22 \%$ was released by thrombin and recovered in the arachidonic acid spot after thin-layer chromatography. In the same experiment, the arachidonic spot in a control sample (no thrombin) contained $12 \%$ of the ${ }^{14} \mathrm{C}$, and this was not increased by addition of heparin.

Because enhancement by heparin of platelet reactivity appeared to be more vigorous with low molecular weight heparin fractions of low antithrombin affinity than with fractions of similar molecular weight with high affinity for antithrombin, it seemed possible that reaction of the heparin with AT inhibited heparinplatelet interaction. Analogous observations have been made concerning the behavior of some heparin-coated surfaces (48). To investigate this question, platelets were washed on an albumin gradient and were resus- pended either in citrated PPP that had been depleted of AT by passage through a heparin-Sepharose column (see Methods) or in normal PPP from the same donor. In reconstituted normal PRP, low molecular-weight heparin of high antithrombin affinity was significantly less active in enhancement of ADP-induced aggregation than were the other fractions, but in antithrombinpoor plasma, the heparin fractions were indistinguishable (Table IV). When purified antithrombin was added back to the antithrombin-poor plasma (final concentration $200 \mu \mathrm{g} / \mathrm{ml}$ ), the low molecular weight high affinity fraction once more became less reactive than the other fractions.

\section{DISCUSSION}

We have shown that porcine mucosal heparin at a concentration of $10 \mu \mathrm{g} / \mathrm{ml}$ or less induces platelet aggregation in citrated PRP, but not in a suspension in Tyrode's buffer of platelets washed by centrifugation through an albumin gradient and then by gel filtration. Heparin also enhances aggregation and serotonin release induced by other agents. Platelet aggregation by heparin is blocked by EDTA and by substances that elevate platelet cyclic AMP but not by inhibitors of arachidonic acid cyclooxygenase or by hirudin. The platelet response to heparin does not seem to require the involvement of ADP, because it is not inhibited by $N$-amylthio$5^{\prime}$-AMP or apyrase.

These conclusions are to be contrasted with those of Eika $(28,57)$, who observed in suspensions of washed platelets aggregation induced by much higher heparin concentrations $(70 \mathrm{U} / \mathrm{ml}$, roughly $6-500$ times greater than the concentration employed in these experiments). The platelet response observed by Eika was blocked by aspirin and apyrase, and he concluded that it resulted from ADP released from platelets by heparin.

Zucker and associates (27) observed that heparininduced platelet clumping was blocked by a combination of creatine phosphate and creatine phosphokinase

TABLE IV

Enhancement of ADP-induced Platelet Aggregation in Reconstituted Normal or Antithrombin-poor PRP or Antithrombin-poor PRP with AT added; $\triangle \mathrm{OD}$

\begin{tabular}{lccc}
\hline & $\begin{array}{c}\text { Reconstituted } \\
\text { normal PRP }\end{array}$ & $\begin{array}{c}\text { Antithrombin- } \\
\text { poor } \\
\text { PRP }\end{array}$ & $\begin{array}{c}\text { Antithrombin- } \\
\text { poor } \\
\text { PRP + AT }\end{array}$ \\
\hline LMW-LAT* $^{*}$ & $12.1 \pm 6.0$ & $10.8 \pm 5.6$ & $12.3 \pm 4.0$ \\
LMW-HAT & $9.5 \pm 6.0$ & $11.1 \pm 8.1$ & $9.7 \pm 3.9$ \\
$n$ & 32 & 30 & 9 \\
$P$ & 0.001 & NS & 0.063 \\
\hline
\end{tabular}

LMW-HAT and LMW-LAT fractions were compared in portions of the same reconstituted PRP sample. Analysis was by Student's $t$ test for paired data (Mean \pm SD.)

* See Table I for definitions of abbreviations. 
but did not identify the heparin preparation or report its concentration. They also attributed the reaction to released ADP. Thomson et al. (29) reported findings similar to those observed in our experiments; namely, enhancement of ADP- and epinephrine-induced platelet aggregation and serotonin release in citrated PRP, the second phase of which was susceptible to inhibition by aspirin. The primary phase of aggregation was enhanced by heparin in Thomson's studies, and this effect was not inhibited by aspirin.

These actions of stock pharmaceutical grade porcine mucosal heparin are also displayed in varying degree by subfractions separated on the basis of molecular weight and antithrombin affinity. Several authors have reported variations in the specific anticoagulant activity of heparin fractions, with a trend toward increasing activity at higher molecular weight $(32,58,59)$. Laurent et al. (60) attributed this relationship to an increased possibility that reactive sites for antithrombin will be present in a given heparin molecule as the molecular weight increases. On the other hand, Rosenberg and associates $(31,44)$ have described heparin fractions of either high or low antithrombin affinity with the same molecular weight. They have recently suggested (61) that the $20,000 \mathrm{~mol}$ wt fractions with high antithrombin affinity have two antithrombin binding sites per molecule.

We found high molecular weight fractions to be more active than low molecular weight fractions in induction of platelet aggregation and in enhancement of aggregation induced by other agonists. Within a fraction of given molecular weight, platelet reactivity did not parallel anticoagulant activity. In high molecular weight fractions, antithrombin affinity appeared to have no relation to platelet reactivity. In low molecular weight preparations, there was a roughly reciprocal relationship between potency in induction of platelet aggregation or in enhancement of platelet aggregation by other agonists and antithrombin binding affinity, low affinity fractions being significantly more reactive toward platelets than high affinity fractions. Eika (62) reported that chemical alterations of heparin altered its anticoagulant effectiveness and platelet reactivity in parallel, but his heparin preparation was composed of a heterogeneous population of heparin molecules. His conclusion does not appear to be true for fractions of uniform molecular weight.

In PRP depleted of AT, low molecular weight heparin fractions of high or low AT affinity were equivalent in enhancement of ADP-induced aggregation, but when the AT concentration was restored by adding back purified AT, a difference in behavior of the two fractions reappeared, comparable to the difference in normal PRP. These results suggest that antithrombin inhibits heparin-platelet interactions. Shanberge et al. (63) have reported that platelets bind heparin but not heparin-antithrombin complexes. Inhibition by antithrombin of heparin-induced reactions of platelets was also suggested in studies by Lindon et al. (48) of solid-phase heparin immobilized on Sepharose beads. Heparin-platelet interaction was reduced by preliminary incubation of the beads with normal platelet-free plasma or solutions of purified antithrombin but not by antithrombin-poor plasma. Other surfaces with heparin covalently linked have shown similar properties (64).

These observations are consistent with the existence of two types of binding sites on the heparin molecule; one that binds either to AT or to platelets but has a higher affinity for the former, and a second, perhaps the balance of the molecule, that binds preferentially to platelets. In the heparin fractions of low molecular weight, the former binding sites would appear to predominate in the high antithrombin affinity subfractions, so that, if exposed to antithrombin, these molecules are unlikely to react with platelets. The low antithrombin affinity subfractions of low molecular weight, whose few antithrombin binding sites may in fact be the result of contamination, react more strongly with platelets. In the high molecular weight heparin fractions, the molecules are apparently large enough to offer ample sites for reaction with platelets, regardless of the presence or absence of additional sites that bind antithrombin.

The failure of heparin to aggregate platelets suspended in a buffer after albumin washing and gel filtration suggests a requirement for a plasma cofactor. Heparininduced platelet aggregation thus resembles platelet clumping induced by the antibiotic ristocetin, according to mechanisms proposed by Coller and Gralnick (65). However, the plasma factor involved appears to be different from von Willebrand's factor, the plasma component required by ristocetin. Heparin-induced platelet aggregation is severely depressed in a solution of $25 \%$ PPP in Tyrode's buffer and does not occur with formaldehyde-fixed platelets, although these conditions support a vigorous platelet response to ristocetin.

Two thrombocytopenic syndromes have been described in patients receiving heparin: a transient, usually minor, reduction in platelet count occurring shortly after each intravenous injection, and a more severe sustained thrombopenia occurring 5-9 d after the initiation of heparin therapy. The former problem is reported to be almost universally present among patients who receive heparin (7). It seems likely that the fall in platelet count that immediately follows an injection of heparin results from sequestration of platelets aggregated by the mechanism described in this report. A similar process may be involved in cases of arterial embolism attributed to heparin therapy (15-17).

Because low molecular weight heparin fractions of 
high antithrombin affinity appear to have reduced reactivity with platelets, an improvement in clinical anticoagulant therapy could probably be achieved by use of such fractions, which would be expected to maximize anticoagulant potency with a minimum of undesirable side effects on platelets. Such a prospect also offers hope for an improvement in the blood compatibility of heparin-coated artificial surfaces intended to function as thrombo-resistant materials in prosthetic devices such as artificial heart valves or pump oxygenators for cardiopulmonary bypass.

\section{ACKNOWLEDGMENTS}

We thank Dr. Bernard Ransil for help with the statistical analysis.

This work was supported by grants HL 11414, HL 20079, HI 13754, and HL 19131 from the National Heart, Lung, and Blood Institute.

\section{REFERENCES}

1. Rosenberg, R. D. 1975. Actions and interactions of antithrombin and heparin. N. Engl. J. Med. 292: 146-151.

2. Berger, S., and E. W. Salzman. 1974. Thromboembolic complications of prosthetic devices. In Progress in Hemostasis and Thrombosis. T. H. Spaet, editor. Grune \& Stratton, Inc., New York. 2: 273-309.

3. Lindsay, R. M., C. R. M. Prentice, J. F. Davidson, J. A. Burton, and G. P. McNicol. 1972. Haemostatic changes during dialysis associated with thrombus formation on dialysis membranes. Br. Med. J. 4: 454-458.

4. Baumgartner, H. R., M. B. Stemerman, and T. H. Spaet. 1971. Adhesion of blood platelets to subendothelial surface: distinct from adhesion to collagen. Experientia (Basel). 27: 28.3-285.

5. Salzman, E. W. 1965. On the limitations of heparin after arterial reconstruction. Surgery (St. Louis). 57: 131-138.

6. Friedman, L. I., H. Liem, E. F. Grabowski, E. F. Leonard, and C. W. McCord. 1970. Inconsequentiality of surface properties for initial platelet adhesion. Trans. Am. Soc. Artif. Intern. Organs. 16: 63-73.

7. Gollub, S., and A. W. Ulin. 1962. Heparin-induced thrombocytopenia in man. J. Lab. Clin. Med. 59: 430-435.

8. Bell, W. R., P. A. Tomasulo, B. M. Alving, and T. P. Duffy. 1976. Thrombocytopenia occurring during the administration of heparin. A prospective study in 52 patients. Ann. Intern. Med. 85: 155-160.

9. Rhodes, G. R., R. H. Dixon, and D. Silver. 1977. Heparin induced thrombocytopenia: eight cases with thrombotic hemorrhagic complications. Ann. Surg. 186: 752-758.

10. Green, D., K. Harris, N. Reynolds, M. Roberts, and R. Patterson. 1978. Heparin immune thrombocytopenia: evidence for a heparin-platelet complex as the antigenic determinant. J. Lab. Clin. Med. 91: 167-175.

11. Nelson, J. C., R. G. Lerner, R. Goldstein, and N. A. Cagin. 1978. Heparin-induced thrombocytopenia. Arch. Intern. Med. 138: 548-552.

12. Fratantoni, J. C., R. Pollet, and H. R. Gralnick. 1975. Heparin-induced thrombocytopenia: confirmation of diagnosis with in vitro methods. Blood. 45: 395-401.

13. Natelson, E. A., E. C. Lynch, C. P. Alfrey, and J. B. Gross. 1969. Heparin-induced thrombocytopenia. An unexpected response to treatment of consumption coagulopathy. Ann. Intern. Med. 71: 1121-1125.

14. Babcock, R. B., C. W. Dumper, and W. B. Scharfman. 1976.
Heparin-induced immune thrombocytopenia. N. Engl. J. Med. 295: 237-241.

15. Roberts, B., F. E. Rosato, and E. F. Rosato. 1964. Heparin -a cause of arterial emboli? Surgery (St. Louis). 55: 803-808.

16. Weismann, R. E., and R. W. Tobin. 1958. Arterial embolism occurring during systemic heparin therapy. Arch. Surg. 76: 219-227.

17. Baird, R. A., and F. R. Convery. 1977. Arterial thromboembolism in patients receiving systemic heparin therapy. A complication associated with heparin-induced thrombocytopenia. J. Bone Jt. Surg. Am. Vol. 59A: 1061-1064.

18. Lindsay, R. M., J. T. B. Rourke, B. D. Reid, A. L. Linton, T. Gilchrist, J. Courtney, and R. W. Edwards. 1977. The role of heparin on platelet retention by acrylonitrile copolymer dialysis membranes. J. Lab. Clin. Med. 89: 724734.

19. Lagergren, H. R., and J. C. Eriksson. 1971. Plastics with a stable surface monolayer of cross-linked heparin: preparation and evaluation. Trans. Am. Soc. Artif. Intern. Organs. 17: 10-12.

20. Najjar, F. B., and V. L. Gott. 1970. The use of small diameter dacron grafts with wall-bonded heparin for venous and arterial replacement: canine studies and preliminary clinical experience. Surgery (St. Louis). 68: 1053-1063.

21. Valiathan, M. S., C. S. Weldon, H. W. Bender, S. R. Topaz, and V. L. Gott. 1968. Resection of aneurysms of the descending thoracic aorta using a GBH-coated shunt bypass. J. Surg. Res. 8: 197-205.

22. Schmer, G., L. N. L. Teng, J. J. Cole, J. E. Vizzo, M. M. Francisco, and B. H. Scribner. 1976. Successful use of a totally heparin grafted hemodialysis system in sheep. Trans. Am. Soc. Artif. Intern. Organs. 22: 654-663.

23. O'Brien, J. R., S. M. Shoobridge, and W. J. Finch. 1969. Comparison of the effect of heparin and citrate on platelet aggregation. J. Clin. Pathol. (Lond.). 22: 28-31.

24. Besterman, E. M. M., and M. P. T. Gillett. 1973. Heparin effects on plasma lysolecithin formation and platelet aggregation. Atherosclerosis. 17: 503-513.

25. Gillett, M. P. T., and E. M. M. Besterman. 1973. Effects of heparin derived from different tissues on plasma phospholipids and platelet aggregation. Lancet. II: 1204-1206.

26. Eika, C. 1972. On the mechanism of platelet aggregation induced by heparin, protamine and polybrene. Scand. J. Haematol. 9: 248-257.

27. Zucker, M. B. 1977. Heparin and platelet function. Fed. Proc. 36: 47-49.

28. Eika, C. 1971. Inhibition of thrombin induced aggregation of human platelets in heparin. Scand. J. Haematol. 8: 216-222.

29. Thomson, C., C. D. Forbes, and C. R. M. Prentice. 1973. The potentiation of platelet aggregation and adhesion by heparin in vitro and in vivo. Clin. Sci. Mol. Med. 45: 485-494.

30. Ellison, N., L. H. Edmunds, Jr., and R. W. Colman. 1978. Platelet aggregation following heparin and protamine administration. Anesthesiology. 48: 65-68.

31. Lam, L. H., J. E. Silbert, and R. D. Rosenberg. 1976. The separation of active and inactive forms of heparin. Biochem. Biophys. Res. Commun. 69: 570-577.

32. Andersson, L-O., T. W. Barrowcliffe, E. Holmer, E. A. Johnson, and G. E. C. Sims. 1976. Anticoagulant properties of heparin fractionated by affinity chromatography on matrix-bound antithrombin III and by gel filtration. Thromb. Res. 9: 575-583.

33. Höök, M., I. Bjork, J. Hopwood, and U. Lindahl. 1976 Anticoagulant activity of heparin: separation of high activity and low-activity heparin species by affinity 
chromatography on immobilized antithrombin. Febs (Fed. Eur. Biochem. Soc.) Lett. 66: 90-93.

34. Rosenberg, R. D., and L. Lam. 1979. Correlation between structure and function of heparin. Proc. Natl. Acad. Sci. U. S. A. 76: 1218-1222.

35. Lindon, J. N., R. Rodvien, D. Brier, R. Greenberg, E. Merrill, and E. W. Salzman. 1978. In vitro assessment of interaction of blood with model surfaces. J. Lab. Clin. Med. 92: 904-915.

36. Tangen, O., H. S. Berman, and P. Marfey. 1971. Gel filtrations: a new technique for separation of platelets from plasma. Thromb. Diath. Haemorrh. 25: 268-278.

37. Lindon, J. N., R. Rodvien, and D. W. Waugh. 1976. Effects of matrix contact during gel filtration of human platelets in plasma. Thromb. Diath. Haemorrh. 36: 311-318.

38. Timmons, S., and J. Hawiger. 1978. Separation of human platelets from plasma proteins including factor $\mathrm{VIII}_{\mathrm{VwF}}$ by a combined albumin gradient-gel filtration method using hepes buffer. Thromb. Res. 12: 297-306.

39. Born, G. V. R., and M. J. Cross. 1963. The aggregation of blood platelets. J. Physiol. 168: 179-195.

40. Spaet, T. H., and M. B. Zucker. 1964. Mechanism of platelet plug formation and role of adenosine diphosphate. Am. J. Physiol. 206: 1267-1274.

41. McMillan, R. M., D. E. MacIntyre, and J. L. Gordon. 1977. Simple, sensitive fluorimetric assay for malondialdehyde production by blood platelets. Thromb. Res. 11: $425-428$.

42. Lapetina, E. G., C. J. Schmitges, K. Chandrabose, and P. Cuatrecasas. 1977. Cyclic adneosine 3',5'monophosphate and prostacyclin inhibit membrane phospholipase activity in platelets. Biochem. Biophys. Res. Commun. 76: $828-835$.

43. Flower, R. J. 1974. Drugs which inhibit prostaglandin biosynthesis. Pharmacol. Rev. 26: 33-67.

44. Rosenberg, R. D., G. Armand, and L. Lam. 1978. Structurefunction relationships of heparin species. Proc. Natl. Acad. Sci. U. S. A. 75: 3065-3069.

45. Whigham, K. A. E., A. H. Drummond, W. Edgar, and C. R. M. Prentice. 1976. A method for the removal of platelet aggregating activity of commercial apyrase. Thromb. Haemostasis. 36: 652-653.

46. Lindon, J., R. Rosenberg, E. Merrill, and E. Salzman. 1978. Interaction of human platelets with heparinized agarose gel. J. Lab. Clin. Med. 91: 47-59.

47. Rosenberg, R. D., and P. S. Damus. 1976. Antithrombinheparin cofactor. Methods Enzymol. 45: 543-669.

48. Hunter, W. M., and F. C. Greenwood. 1962. Preparation of iodine-131 labelled human growth hormone of high specific activity. Nature (Lond.). 194: 495-496.

49. Salzman, E. W., J. N. Lindon, and R. Rodvien. 1976. Cyclic AMP in human blood platelets: relation to platelet prostaglandin synthesis induced by centrifugation or surface contact. J. Cyclic Nucleotide Res. 2: 25-37.

50. Snedecor, G. W., and W. G. Cochran. 1967. Statistical
Methods. Iowa State University Press, Ames, Iowa. 6th edition. 258-296.

51. Steel, R. G. D., and J. H. Torrie. 1960. Principles and Procedures of Statistics. McGraw-Hill Book Company, Inc., New York. 107-109.

52. Hollender, M., and D. A. Wolfe. 1973. Nonparametric Statistical Methods. John Wiley \& Sons, Inc., New York. 115-116, 162-167.

53. Coller, B. S., B. R. Franza, Jr., and H. R. Gralnick. 1976. The $\mathrm{pH}$ dependence of quantitative ristocetin-induced platelet aggregation: theoretical and practical implications-a new device for maintenance of platelet rich plasma pH. Blood. 47: 841-853.

54. Macintyre, D. E., J. L. Gordon, A. H. Drummond, M. Steer, and E. W. Salzman. 1977. Specific inhibition of ADP-induced platelet response by 2-n-amylthio AMP. Thromb. Haemostasis. 38: 6.

55. Ardlie, N. G., D. W. Perry, M. A. Packham, and J. F Mustard. 1971. Influence of apyrase on stability of suspensions of washed rabbit platelets (35419). Proc. Soc. Exp. Biol. Med. 136: 1021-1023.

56. Olivekrona, T., G. Bengtsson, S. E. Marklund, U. Lindahl, and M. Höök. 1977. Heparin-lipoprotein lipase interactions. Fed. Proc. 36: 60-65.

57. Eika, C. 1972. The platelet aggregating effect of eight commercial heparins. Scand. J. Haematol. 9: 480-482.

58. Shen, L. L., G. H. Barlow, and W. H. Holleman. 1978. Differential activities of heparins in human plasma and in sheep plasma. Effects of heparin molecular sizes and sources. Thromb. Res. 13: 671-679.

59. Lane, D. A., I. R. Macgregor, R. Michalski, and V. V'. Kakkar. 1978. Anticoagulant activities of four unfractionated and fractionated heparins. Thromb. Res. 12: $257-271$.

60. Laurent, T. C., A. Tengblad, L. Thunberg, M. Höök, and U. Lindahl. 1978. Molecular weight dependance of the anticoagulant activity of heparin. Biochem. J. 175: 691701.

61. Rosenberg, R. D., R. E. Jordan, L. V. Favreau, and L. H. Lam. 1979. High active heparin species with multiple binding sites for antithrombin. Biochem. Biophys. Res. Commun. 86: 1319-1324.

62. Eika, C. 1973. Anticoagulant and platelet aggregating activities of heparin. Thromb. Res. 2: 349-360.

63. Shanberge, J. N., J. Kambayashi, and M. Nakagawa. 1976. The interaction of platelets with a tritium-labelled heparin. Thromb. Res. 9: 595-609.

64. Lindon, J., D. Brier-Russell, M. Silane, M. Smith, D. Labarre, A. Dincer, R. Rosenberg, E. Merrill, and E. Salzman. 1979. Heparin-coated surfaces that bind antithrombin have reduced platelet reactivity. Thromb. Haemostasis. 42: 131.

65. Coller, B. W., and H. R. Gralnick. 1977. Studies on the mechanism of ristocetin-induced platelet agglutination. Effects of structural modification of ristocetin and vancomycin. J. Clin. Invest. 60: 302-312. 